\section{Hubs to address materials needs}

\author{
www.energy.gov/hubs
}

according to Alex Larzelere, director for Advanced Modeling and Simulation for the Department of Energy (DOE) Office of Nuclear Energy.

Christopher Stanek, who leads the Materials Performance and Optimization (MPO) technical focus group at CASL, said that this top-down focus leads to the explicit consideration of materials science issues that govern phenomena such as fuel clad interactions, fretting, and the buildup of deposits on the fuel's cladding, known as CRUD.

"MPO will address these materials issues by delivering multiphysics, multiscale modeling and simulation capabilities to the CASL Virtual Reactor," Stanek said. "MPO will provide innovative, science-based solutions to applied, industrially defined problems."

Many of the hub members will be based at CASL headquarters in Oak Ridge National Laboratory; however, various partner sites will be integrated through real-time, virtual collaboration capabilities. CASL will also work closely with Energy Frontier Research Centers and DOE Nuclear Energy programs. Stanek said, "This and other DOE Energy Innovation Hubs are exciting opportunities for the computational and experimental materials science communities."

\section{Fuels from sunlight}

The Fuels from Sunlight Energy Innovation Hub will be run by the Joint Center for Artificial Photosynthesis (JCAP), a team led by the California Institute of Technology (Caltech). The hub is charged with taking the field of solar fuels from fundamental research into applied research and technology development, according to Eric Rohlfing, director of the Chemical Sciences, Geosciences, and Biosciences Division for the DOE Office of Basic Energy Sciences.

A lot of materials have to be discovered and implemented in order for this to happen. For example, an artificial photosynthesis system will require light absorbers that are cheap, efficient, and robust along with soft material membranes that separate the reactants and products while providing ionic pathways and good optical and light-scattering properties. 
"JCAP will take advantage of our amazing ability to design, discover, characterize, and integrate new materials with all the functions required to create a true solar fuels generation system: light absorbers, catalysts, separation membranes, and linkers for energy and charge transduction," said Rohlfing, "The challenge is not insignificant, but the potential benefit is enormous and this task is ideally suited to an Energy Innovation Hub."

The hub will have two physical locations, one at Caltech and one at Lawrence Berkeley National Laboratory, but the two will work under a unified management structure and under one virtual roof, incorporating video conferencing and other collaborative tools. The hub will also be an integrated part of the broader materials community, according to JCAP Director Nathan Lewis, and will work with Energy Frontier Research Centers, principal investigators, and other teams.

"A large part of what JCAP is going to do is to take the best materials and newly discovered materials from the broader community and accelerate the rate at which they can be incorporated into devices," Lewis said.

\section{Energy efficient buildings}

The buildings hub is the central component of the Greater Philadelphia Innovation Cluster (GPIC) for Energy Efficient Buildings, a research consortium led by the Pennsylvania State University (Penn State). GPIC is funded by a multi-agency initiative to link efforts in energy efficient buildings with business development and economic growth, called an Energy Regional Innovation Cluster (E-RIC).

The hub aims to develop technologies, designs, and systems that can increase energy efficiency and reduce carbon emissions from new and existing buildings. "We lose so much energy through the roofs and the walls of commercial buildings around the U.S. that we have to do something," said Henry Foley, Vice President for Research and Dean of the
Graduate School at Penn State. A major challenge, he said, is to retrofit buildings with materials that are energy efficient but also create a healthy and livable environment for occupants.

Materials will play a vital role in improving energy efficiency in buildings, from providing green, healthy insulation to utilizing new, state-of-the art composites. "I think it's going to be a great opportunity for the new materials community to really showcase the kind of breakthroughs they've been making in the last 10 years," said Foley. In particular, he said, since academic institutions, national laboratories, and corporations will be working together closely.

GPIC will be located in the Philadelphia Navy Yard, a 1200-acre former Navy base that in many ways acts as a city within a city. The yard has an independent grid and over 200 buildings that range from offices to factories, making it an attractive test site for new designs.

Kendra Redmond
EC advocates for new "green car" research proposals http://cordis.europa.eu/fp7

D uring the Seventh Framework Programme (FP7) Information Day held in Brussels in July, European Commission officials urged potential researchers to put forward new proposals for research under the "Green Cars" public-private partnership (PPPs).

A total of $€ 3.2$ billion has been earmarked for European public-private partnerships dedicated to the development of new technologies in the manufacturing, construction, and automotive sectors. Now, a second call for proposals, "FP7-SST-2011-RTD-1," published on July 20, 2010, is set to inject $€ 40.25$ million into the key market area of sustainable surface transport.

Specific topics covered in this call include a wide range of pressing road transport-related issues, from electric vehicle safety to urban and inter-urban shipping to integrated intermodal traveler services, and eco-design and manufacturing processes for batteries and electrical components. The use of information and communication technologies and the manufacturing of batteries and electrical components are also covered. The deadline for proposals is December 2, 2010.

The "Info Day" held in Brussels was aimed at informing participants about the progress of research already initiated under the PPPs and about the second round of cross-thematic coordinated calls.

At a special session on the "Green Cars" PPP, the Director of Transport at the European Commission's Research Directorate-General, András Siegler, said, "The transition to greener vehicles in Europe is an important one. It is needed to sustain our automotive industry, our environment, and our mobility."

The Green Cars initiative is one of the three PPPs included in the European Commission's 2008 economic recovery package. It makes available $€ 5$ billion to boost the automotive industry and to support the development of new, sustainable forms of road transport. Of this sum, $€ 4$ billion are being made available through loans by the European Investment Bank. The remaining $€ 1$ billion is being provided under the EU's Research Framework Programme and by the private sector.

Full details on the topics covered by the new call, and information on how to submit a proposal, are available on the CORDIS Web site at http://cordis. europa.eu/fp7. 


\section{CUSTOMIZED PRODUCTION ION IMPLANTERS}

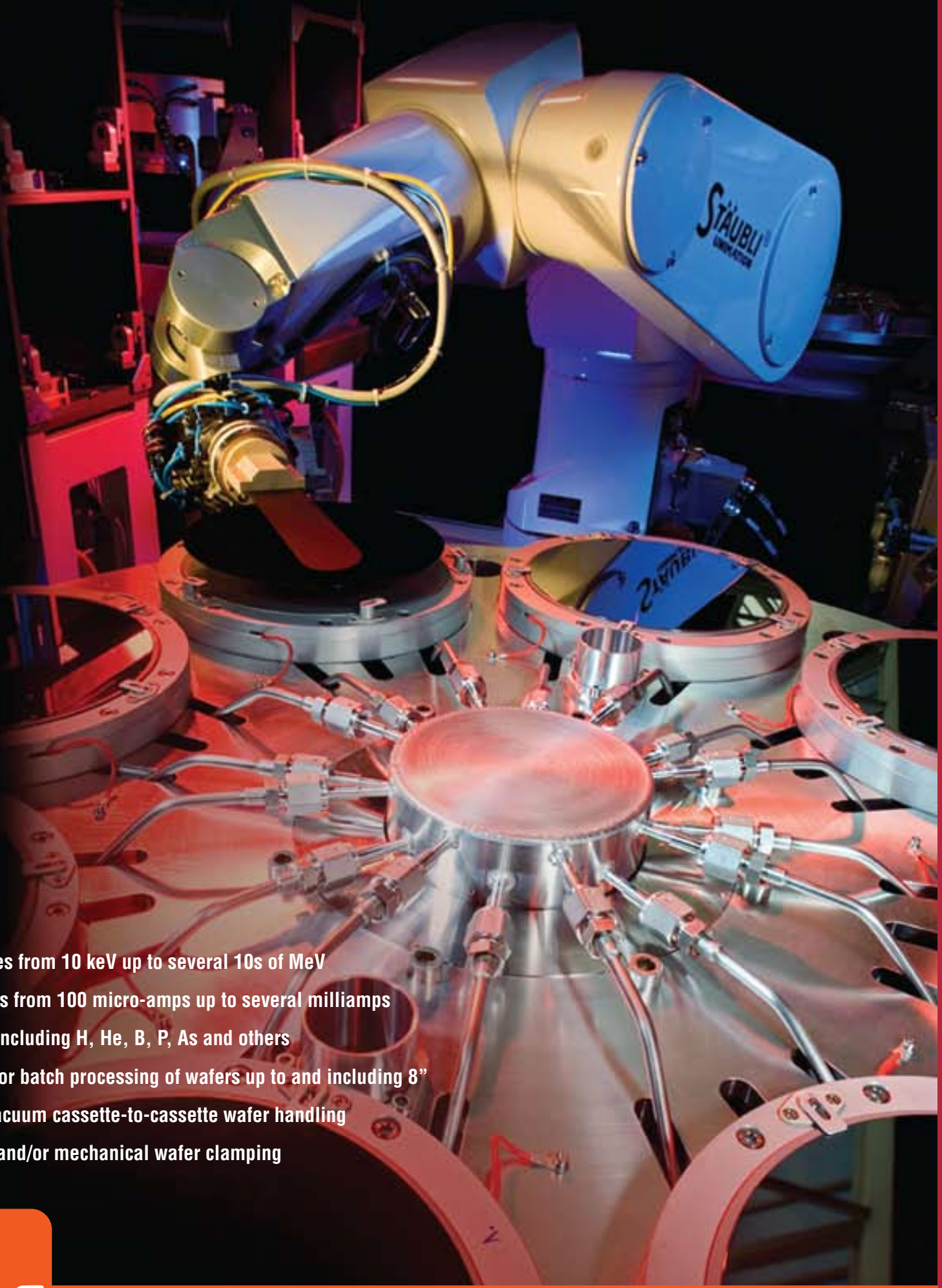

Beam energies from $10 \mathrm{keV}$ up to several 10 s of Me

Beam currents from 100 micro-amps up to several milliamps

Ion species, including H, He, B, P, As and others

- Single wafer or batch processing of wafers up to and including 8 "

- In-air or in-vacuum cassette-to-cassette wafer handling

- Electrostatic and/or mechanical wafer clamping

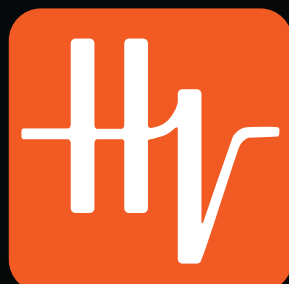

\section{High Voltage Engineering}

High Voltage Engineering Europa B.V.

P.O. Box 99, 3800 AB Amersfoort, The Netherlands

Tel: 31334619741 • info@highvolteng.com

www.highvolteng.com 